Rita Christiane Baron, Lorenz Risch, Myriam Weber, Sarah Thiel, Kirsten Grossmann, Nadia Wohlwend, Thomas Lung, Dorothea Hillmann, Michael Ritzler, Susanna Bigler, Konrad Egli, Francesca Ferrara, Thomas Bodmer, Mauro Imperiali, Sonja Heer, Harald Renz, Lukas Flatz, Philipp Kohler, Pietro Vernazza, Christian R. Kahlert, Matthias Paprotny and Martin Risch*

\title{
Frequency of serological non-responders and false-negative RT-PCR results in SARS-CoV-2 testing: a population-based study
}

https://doi.org/10.1515/cclm-2020-0978

Received June 25, 2020; accepted August 12, 2020; published online August 31, 2020

\begin{abstract}
Objectives: The sensitivity of molecular and serological methods for COVID-19 testing in an epidemiological setting is not well described. The aim of the study was to determine the frequency of negative RT-PCR results at first clinical presentation as well as negative serological results after a follow-up of at least 3 weeks.
\end{abstract}

Methods: Among all patients seen for suspected COVID-19 in Liechtenstein $(n=1921)$, we included initially RT-PCR positive index patients $(n=85)$ as well as initially RT-PCR

Rita Christiane Baron, Lorenz Risch, Matthias Paprotny, and Martin Risch contributed equally to this work.

*Corresponding author: Dr. med. Martin Risch, Zentrallabor, Kantonsspital Graubünden, Loësstrasse 170, 7000 Chur, Switzerland. Phone: +41 8125665 30, E-mail: martin.risch@ksgr.ch

Rita Christiane Baron, Psychiatrische Klinik Waldhaus, Chur, Switzerland, E-mail: rch.baron@gmail.com

Lorenz Risch, Labormedizinisches zentrum Dr. Risch, Buchs, Switzerland; Private Universität im Fürstentum Liechtenstein, Triesen, Liechtenstein; and Center of Laboratory Medicine, University Institute of Clinical Chemistry, University of Bern, Bern, Switzerland, E-mail: lorenz.risch@risch.ch Myriam Weber, Sarah Thiel and Matthias Paprotny, Liechtensteinisches Landesspital, Heiligkreuz, Vaduz, Liechtenstein, E-mail: myriamw@bluewin.ch (M. Weber), sarah.thiel@bluewin.ch (S. Thiel), Matthias.Paprotny@landesspital.li (M. Paprotny) Kirsten Grossmann, Private Universität im Fürstentum Liechtenstein, Triesen, Liechtenstein, E-mail: kirsten.grossmann@risch.ch Nadia Wohlwend, Thomas Lung, Dorothea Hillmann, Michael Ritzler and Francesca Ferrara, Labormedizinisches zentrum Dr. Risch, Buchs, Switzerland, E-mail: nadia.wohlwend@risch.ch (N. Wohlwend), thomas.lung@risch.ch (T. Lung), dorothea.hillmann@risch.ch (D. Hillmann), michael.ritzler@risch.ch (M. Ritzler), francesca.ferrara@risch.ch (F. Ferrara) negative ( $n=66$ ) for follow-up with SARS-CoV-2 antibody testing. Antibodies were detected with seven different commercially available immunoassays. Frequencies of negative RT-PCR and serology results in individuals with COVID-19 were determined and compared to those observed in a validation cohort of Swiss patients $(n=211)$.

Results: Among COVID-19 patients in Liechtenstein, falsenegative RT-PCR at initial presentation was seen in $18 \%$ (12/66), whereas negative serology in COVID-19 patients was $4 \%$ (3/85). The validation cohort showed similar frequencies: 2/66 (3\%) for negative serology, and 16/155 (10\%) for false negative RT-PCR. COVID-19 patients with negative follow-up serology tended to have a longer disease duration $(\mathrm{p}=0.05)$ and more clinical symptoms than other patients with COVID-19 $(\mathrm{p}<0.05)$. The antibody titer

Susanna Bigler, Konrad Egli and Thomas Bodmer, Labormedizinisches zentrum Dr. Risch, Liebefeld, Switzerland,

E-mail: susanna.bigler@risch.ch (A.B.S. Bigler), konrad.egli@risch.ch (K. Egli), thomas.bodmer@risch.ch (T. Bodmer)

Mauro Imperiali, Centro medicina di laboratorio Dr. Risch, Pregassona, Switzerland, E-mail: mauro.imperiali@risch.ch Sonja Heer, Blutspendedienst Graubünden, Chur, Switzerland, E-mail: sonja.heer@blutspende-gr.ch

Harald Renz, Institute of Laboratory Medicine and Pathobiochemistry, Molecular Diagnostics, Philipps University Marburg, Marburg, Germany; University Hospital Giessen and Marburg, Marburg, Germany, E-mail: Harald.Renz@uk-gm.de

Lukas Flatz, Institute of Immunobiology, Kantonsspital St Gallen, St Gallen, Switzerland, E-mail: Lukas.Flatz@kssg.ch Philipp Kohler and Pietro Vernazza, Cantonal Hospital St Gallen, Department of Infectious Diseases and Hospital Epidemiology, St Gallen, Switzerland, E-mail: Philipp.Kohler@kssg.ch (P. Kohler), pietro.vernazza@kssg.ch (P. Vernazza)

Christian R. Kahlert, Cantonal Hospital St Gallen, Department of Infectious Diseases and Hospital Epidemiology, St Gallen, Switzerland; Children's Hospital of Eastern Switzerland, Departments of Infectious Diseases and Hospital Epidemiology, St Gallen, E-mail: Christian.Kahlert@kssg.ch. https://orcid.org/0000-00020784-3276 
from quantitative immunoassays was positively associated with the number of disease symptoms and disease duration $(\mathrm{p}<0.001)$.

Conclusions: RT-PCR at initial presentation in patients with suspected COVID-19 can miss infected patients. Antibody titers of SARS-CoV-2 assays are linked to the number of disease symptoms and the duration of disease. One in 25 patients with RT-PCR-positive COVID-19 does not develop antibodies detectable with frequently employed and commercially available immunoassays.

Keywords: antibodies; COVID-19; prevalence; RT-PCR; SARS-CoV-2; sensitivity; serum; specificity.

\section{Introduction}

Coronavirus disease 2019 (COVID-19) is a global pandemic caused by the severe acute respiratory syndrome coronavirus 2 (SARS-CoV-2). COVID-19 is primarily diagnosed based on clinical signs and symptoms together with laboratory measurements and radiological exams such as computed tomography (CT) [1, 2]. For the diagnosis of acute disease, demonstrating the presence of the virus by reverse transcriptase real-time polymerase chain reaction (RT-PCR) is commonly employed [1]. Diagnosis of COVID19 for surveillance purposes or post hoc in patients with suspicion of COVID-19 in the past, which for several reasons was not diagnosed by RT-PCR (e.g., no test done due to a lack of access to testing, negative RT-PCR test despite suggestive clinical or radiological symptoms), is commonly done by testing specific antibodies directed against protein targets of SARS-CoV-2 [1-7].

Commercially available serological assays commonly measure antibodies against either nucleocapsid protein $(\mathrm{N})$ or spike protein $(\mathrm{S})[8,9]$. Even though these antibodies at the moment cannot indicate protective immunity in the future, antibodies directed against $\mathrm{N}$-protein and the receptor-bound determinant (RBD) of S-protein have been shown to closely correlate with neutralizing antibodies [6]. Testing of SARS-CoV-2 antibodies includes either total antibodies or antibody specificities of the IgG, IgA, or IgM isotype. These antibodies commonly develop within 21 days after symptom onset [2]. Even if the common experience with other infectious diseases suggests that antibody dynamics are characterized by the prior appearance of IgM antibodies followed by detectable IgG antibodies, IgG can precede or develop together with the occurrence of IgM or IgA antibodies [2, 10, 11]. The latter case might indicate the presence of pre-existing crossreactive antibodies against other coronavirus [11].
A good test is, inter alia, characterized by low rates of false-positive and false-negative results. There has been a discussion as to why and how frequently false-positive and false-negative results arise in serology as well as RT-PCR tests $[1,12]$. Although regarded as a very specific test, RT-PCR could theoretically deliver false-positive results due to stray viral RNA not originating from a suspected COVID-19 patient but introduced from external sources into the testing process (e.g., cross-contamination from an infected laboratory worker or during sample collection) [1, 13]. Whereas false-positive results in serology testing can be caused by cross-reactivity or analytical interferences, such results carry the risk that an individual will erroneously assume that he or she already contracted COVID-19, followed by a risk of false reassurance, behavioral change, and disease spread [14]. Even greater risk may arise from false negative results in COVID-19 RT-PCR [12, 13]. Kucirka et al. showed that the rate of false-negative RT-PCR results is highly dependent on the timing of nasopharyngeal sampling is being done: the false negative rate was $100 \%$ at 4 days before symptom onset and decreased to $20 \% 3$ days after symptom onset [13]. Another study found a falsenegative rate of $16.7 \%$ for RT-PCR in patients with a clinical suspicion of COVID-19 at initial clinical presentation [15]. Reasons for such false-negative RT-PCR can be a viral load below the lower limit of detection of the employed assay, improper sampling of the nasopharyngeal swab, or decreased viral shedding at the anatomic sampling site [13]. In cases with negative RT-PCR results despite a high pretest probability, repeated testing and testing from alternative sample materials (e.g., endotracheal aspirate, sputum, feces) may be suitable to minimize false-negative rates $[12,16,17]$.

False-negative serology results may occur due to insensitive tests or blood sampling occurring before antibodies develop during the disease course. Antibody positivity in patients with COVID-19 increases over time, with patients usually displaying an antibody response 20 days or more after symptom onset $[14,18]$. It is well known that false-negative antibody results can come from using tests with insufficient diagnostic sensitivity or taking blood samples within the first three weeks after symptom onset. So far, it remains unclear whether a "false-negative serology" can also occur in patients with proven COVID-19 and whose blood samples are taken at least three weeks after symptom onset. In the present study, we aimed to determine the frequency of false-negative RT-PCR/false positive serology tests and false-negative antibody/false positive RT-PCR tests in a population-based setting and provide a clinical description of patients suffering from 
COVID-19 who have discrepant RT-PCR and serology laboratory test results.

\section{Methods}

\section{Study setting and study populations}

This is a national study of COVID-19 cases seen in the Landesspital Liechtenstein, which is the only hospital in the principality of Liechtenstein. Due to a centralized national testing strategy, this institution observed all but one index patient $(n=94)$ diagnosed with COVID-19 in the principality of Liechtenstein during the first wave of the COVID-19 pandemic. Diagnosis of COVID-19 was based on clinical symptoms and RT-PCR testing, which in four cases had to be repeated due to a strong clinical suspicion and initially negative RT-PCR results. The last of the patients in Liechtenstein was diagnosed on April 23rd, 2020. Since then, until submission of this manuscript (June 25th,
2020), no further case has been detected. RT-PCR testing in the principality of Liechtenstein was offered to patients who had a fever of $38^{\circ}$ $\mathrm{C}$ and/or respiratory symptoms together with a possible risk exposure (household, close working contact). As of April 23rd, a total of 2021 tests were performed in 1921 patients. Relative to the country's whole population (38749 at the end of 2019), this corresponded to 5\% (95\% confidence interval (CI) $[4.7,5.2])$ of the national population having undergone testing. All COVID-19 index cases were asked to provide a follow-up venous serum sample at least 3 weeks after the diagnosis of COVID-19 for testing of antibodies directed against SARS-CoV-2. Four of the index patients did not provide consent, whereas one index patient died (with positive serology) before reaching 20 days after symptom onset. Further, the household contacts and close working contacts were invited to provide a serum sample. Some of those close contacts were also tested by RT-PCR primarily due to the presence of symptoms in a high-risk constellation and thus were included in the study. The inclusion algorithm is shown in Figure 1A. The protocol for this analysis was verified by the cantonal ethics commission of the canton of Zurich (KEK ZH; BASEC Nr. Req-2020-00676), which is the

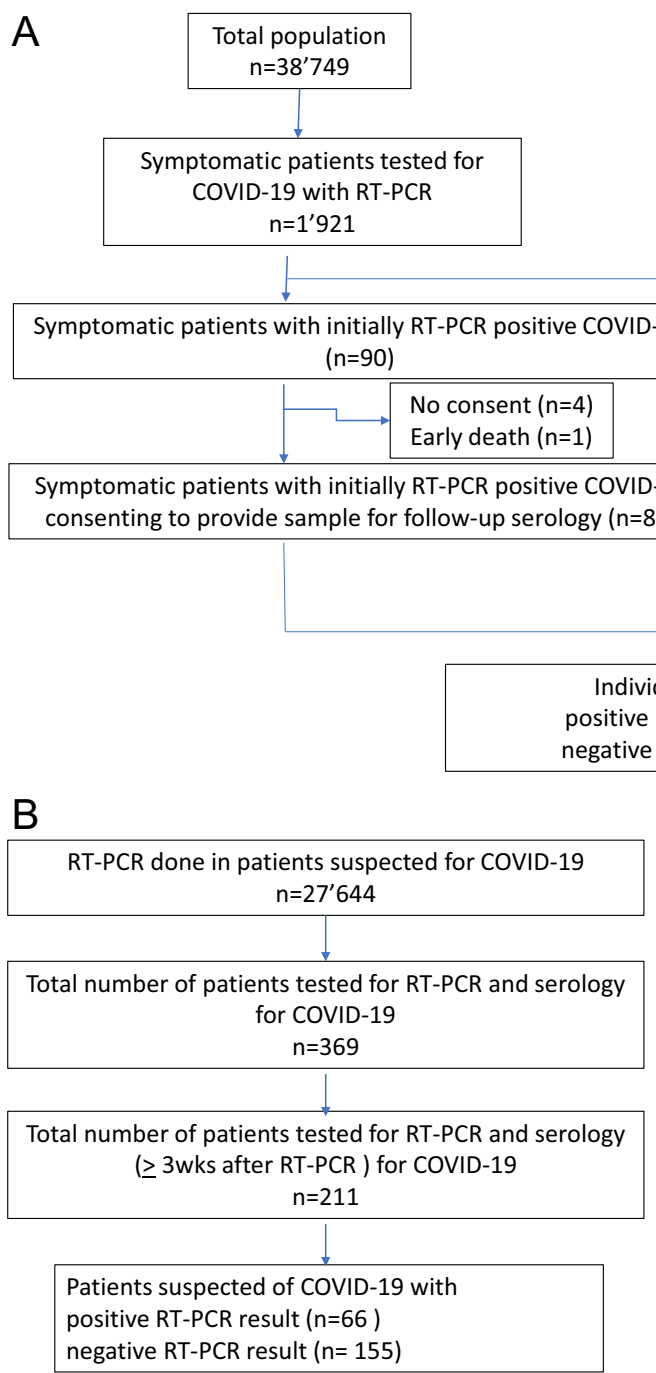

Figure 1: Patient inclusion algorithms. (A) Population-based study in the principality of Liechtenstein; (B) validation cohort in Switzerland. 
competent ethics committee for the principality of Liechtenstein. All study participants provided written informed consent.

To validate the laboratory findings of this population-based study in Liechtenstein, we sought to replicate these frequencies in a validation cohort of patients residing in Switzerland. This validation cohort consisted of patients investigated for clinically suspected COVID-19 by RT-PCR in nasopharyngeal samples at the labormedizinisches zentrum Dr. Risch Ostschweiz AG (Buchs SG, Switzerland) from February 1st, 2020 to May 13th, 2020. If these patients were required to have a follow-up serum sample drawn for anti-SARS-CoV-2 antibodies at least 3 weeks after RT-PCR testing, samples were anonymized and investigated for SARS-CoV-2 antibodies by seven different immunoassay formats. The inclusion algorithm of the validation cohort is given in Figure 1B. The study protocol for this analysis was approved by the ethics board of Eastern Switzerland (EKOS; BASEC Nr. Req-2020-00586), which waived informed consent because it performed laboratory analysis on anonymized samples.

\section{Data collection and measurements}

For each patient, the age, sex, result of SARS-CoV-2 RT-PCR analysis, and number of days from RT-PCR analysis until blood drawing for antibody testing were available. The population-based cohort including household contacts and close working contacts had clinical data (e.g., symptoms and signs, including duration, type of healthcare needed, outcome) available. Patients were followed up periodically with telephone calls (every two to three days), and symptoms were recorded throughout the disease course (i.e., disease duration, hospitalization, fever $>38^{\circ} \mathrm{C}$, coughing, dyspnea, thoracic pressure, fatigue, sore throat, headache, limb pain/myalgia, malaise, diarrhea, nausea, vomitus, running nose, anosmia, ageusia). RT-PCR in Liechtenstein and Switzerland was done on nasopharyngeal swabs run on a COBAS 6800 (Roche Diagnostics, Rotkreuz, Switzerland), BD Max (Becton Dickinson AG, Allschwil, Switzerland), or Cepheid GenXpert (Axon Lab, Baden, Switzerland) using commercially available reagents. As transport media UTM (Copan, Brescia, Italy), UTM (MANTACC, Shenzhen, China), ESwab (Copan, Brescia, Italy), OptiSwab (Axonlab, Baden, Switzerland), VTM (Citotest, Jiangsu, China) and $0.9 \%$ sodium chloride were used. The employed RT-PCR methods have been compared to the Swiss national COVID-19 reference laboratory. If one patient had more than one RT-PCR sample, only the first result was taken for the present analysis, whereas in the case of more than one serum sample, only the last sample was taken for analysis. Serum samples were either analyzed immediately after arrival of the sample in the laboratory or after storing them at $-25^{\circ} \mathrm{C}$. Before placing frozen serum samples in the laboratory analyzers, the samples were kept at room temperature for $4 \mathrm{~h}$ and homogenized by vortexing. For antibody testing using the chemiluminescence technique, antibodies were tested with Elecsys ${ }^{\circledR}$ Anti-SARS-CoV-2 total immunoglobulins (Ig) on a COBAS 6000 by electrochemiluminescence (ECLIA; Roche Diagnostics, Rotkreuz, Switzerland), LIAISON® SARS-CoV-2 S1/S2 IgG run on a Liaison by luminescence immunoassay (LIA; Diasorin, Luzern, Switzerland), and SARS-CoV-2 IgG run on an Architect i2000 by chemiluminescent microparticle immunoassay (CMIA; Abbott diagnostics, Baar, Switzerland), as well as by the EUROIMMUN AntiSARS-CoV-2 ELISA IgG and IgA assays (Euroimmun, Luzern, Switzerland) and the EDI ${ }^{\text {TM }}$ Novel Coronavirus COVID-19 IgG and IgM ELISA kits (Epitope Diagnostics, Inc., San Diego, CA, USA). The ELISAs were run on DSX analyzers (Dynex Technologies, Denkendorf, Germany). All assays were CE-marked. Whereas the Diasorin and
Euroimmun assays detect antibodies against the spike (S) protein, the Roche, Epitope Diagnostics and Abbott Diagnostics assays detect antibodies against the nucleocapsid $(\mathrm{N})$ antigen. Cut-offs for positivity in serum were applied as recommended by the manufacturer: $\geq 1.0$ (COI; cutoff index) for ECLIA, $\geq 1.1$ for S-ELISA (S/C; extinction of the patient sample divided by the extinction of the calibrator), $\geq 1.4$ (S/C) for CMIA, and $\geq 12$ (S/C) for LIA. N-ELISA is a qualitative assay.

\section{Statistical methods}

Continuous variables are given as median and interquartile range [IQR], whereas proportions are given as percentage with 95\% confidence interval (CI). Associations between variables are calculated with Spearman's rank correlation. Proportions are compared using the Chisquare test. Medians of three or more groups were compared using the Kruskal-Wallis test, whereas medians of two groups were compared with the Mann-Whitney $U$ test. The reference standard for determination of disease status consisted of RT-PCR and serology: a patient was considered to have COVID-19 if either a positive RT-PCR result was found and/or two serological assays were positive: one detecting antibodies against $\mathrm{N}$-antigen and one detecting antibodies against $\mathrm{S}$-antigen [19]. Finally, p-values $<0.05$ were considered statistically significant. Medcalc version 18.11.3 (Mariakerke, Belgium) was used for statistical computations.

\section{Results}

\section{Baseline characteristics}

A total of 151 individuals with RT-PCR were included in this population-based study in the principality of Liechtenstein. The median age was 39 years (range 3-84), IQR [27.5, 54.5], and 78 of the individuals were female $(51.3 \%, 95 \%$ CI [ 43.4 , 59.1]). The median time between the testing dates of RT-PCR and SARS-CoV-2 antibodies was 51 days, IQR [47, 54]. Eighty-five (i.e., 56.3\%, 95\% CI [48.3, 64]) patients tested positive by RT-PCR at first clinical presentation. A $2 \times 2$ table of RT-PCR and serology illustrates the results in Table 1A. The median duration of disease was 12 days IQR $[8,17]$ for RT-PCR- and serology-positive patients, 9 days IQR $[6,15]$ for RT-PCR-negative and serology-positive patients, 20 days IQR [16, 34] for RT-PCR-positive and serologynegative patients, and zero days IQR $[0,4]$ (patients with zero days were in fact asymptomatic) for patients with negative serology and RT-PCR. None of the included patients died, though 10 patients were hospitalized to receive oxygen supply and other treatment. None of the patients needed intensive care or mechanical ventilation. Among all investigated patients, antibody titers in quantitative assays positively correlated with the number of symptoms during the disease course as well as disease duration ( $\mathrm{r}$ between 0.48 and 0.54 with $p<0.001$ for all five quantitative assays). There was no significant correlation between antibody titer 
and patient age, sex or the time between RT-PCR testing and antibody testing.

In the validation cohort from Switzerland, a total of 211 patients (145 female; 66 male; median age 50 years (range 15-84), IQR [34, 60] were available after a median of 39, IQR [30, 54] days after PCR testing. Sixty-six of the patients (i.e., 31.3\%, 95\% CI [25.4, 37.8]) had a positive RT-PCR result, whereas 155 had a negative RT-PCR result. The frequencies of the different result combinations are given as a $2 \times 2$ table in Table 1B.

\section{Discrepant samples in the population-based national cohort}

Of the 85 symptomatic patients with positive RT-PCR results, 82 had a positive result of the ECLIA total antibody against $\mathrm{N}$-protein together with a positive result in the IgG ELISA against S-protein. Three $(4 \%, 95 \%$ CI $[1,10])$ had negative results in all seven employed antibody assays (i.e., ECLIA, CMIA, LIA, both ELISA IgG, ELISA IgA, and ELISA IgM). Blood for serological testing was drawn after 53 days in one case and after 54 days in the two other cases. All three patients gave a follow-up sample for repeated antibody testing, which confirmed the initial serological findings. The laboratory results of the patients with positive RT-PCR and negative serology are provided in Table 2A. The clinical characteristics of these patients at presentation are given in Table 2B. All three patients had complete recovery.

Twelve out of the 66 patients with a negative RT-PCR result at first clinical presentation for COVID-19 had a positive antibody result later, corresponding to a proportion of $18 \%$ (95\% CI [11, 29]). Four of these 12 patients had clinical symptoms at presentation and showed a positive RT-PCR result 5, 10, 13, and 31 days after the first negative RT-PCR result, respectively. One patient had no symptoms at clinical presentation, when a negative test result was

Table 1: $2 \times 2$ table of patients with initial RT-PCR result and subsequent serology. (A) in the population of Liechtenstein; (B) validation cohort from Switzerland. Serology was considered positive if one antibody assay against $\mathrm{N}$-antigen was positive and one against $\mathrm{S}$-antigen was positive. Due to rounding, percentages do not necessarily add up to $100 \%$.

A

RT-PCR + RT-PCR -

Serology + $82(54 \%, 95 \% \mathrm{Cl}[46,62] \quad 12(18 \%, 95 \% \mathrm{Cl}[11,29])$ Serology - $\quad 3(2 \%, 95 \% \mathrm{Cl}[1,6]) \quad 54(36 \%, 95 \% \mathrm{Cl}[29,44])$
Table 1b: : $2 \times 2$ table of patients with initial RT-PCR result and subsequent serology. (a) in the population of Liechtenstein; (b) validation cohort from Switzerland. Serology was considered positive if one antibody assay against $\mathrm{N}$-antigen was positive and one against $\mathrm{S}$-antigen was positive. Due to rounding, percentages do not necessarily add up to $100 \%$.

B

\begin{tabular}{rrr}
\hline & RT-PCR + & RT-PCR - \\
\hline Serology + & $63(30 \%, 95 \% \mathrm{Cl}[24,36]$ & $16(8 \%, 95 \% \mathrm{Cl}[5,12])$ \\
Serology - & $2(1 \%, 95 \% \mathrm{Cl}[0.4,5])$ & $139(66 \%, 95 \% \mathrm{Cl}[59,72])$ \\
\hline
\end{tabular}

obtained by RT-PCR. The laboratory results of the patients with negative RT-PCR and positive serology are provided in Table 3A. Their clinical characteristics at presentation are given in Table 3B.

Interestingly, there were significant differences in the number of clinical symptoms of COVID-19 occurring during the disease course among the three different groups (i.e., concordant positive samples, median five IQR [4, 7]; positive RT-PCR with negative serology, 3 [2, 6]; negative RT-PCR with positive serology, 8 [7, 10]; $\mathrm{p}=0.004$, significant differences between all groups, $\mathrm{p}<0.05)$. However, among patients with laboratory evidence of COVID-19 infection, patients with positive RT-PCR but negative serology results had a tendency towards longer disease duration (median 20 days IQR [16, $34]$ vs. $12[8,17] ; \mathrm{p}=0.05)$.

\section{Discrepant samples in the validation cohort}

Two of the 66 RT-PCR-positive patients had negative results in the immunoassays, corresponding to a serological nonresponder percentage of $3 \%(95 \% \mathrm{CI}[1,10])$. Among the 155 RT-PCR-negative patients, $16(10 \%, 95 \%$ CI $[7,16])$ had at least one positive antibody assay against N-protein (i.e., ECLIA, N-ELISA IgG, CMIA, or N-ELISA IgM) as well as one positive antibody assay against S-protein (i.e., LIA, S-ELISA IgG, S-ELISA IgA) positive. Together, the frequencies of negative follow-up serology in RT-PCR-positive patients $(\mathrm{p}=0.73)$ and of positive follow-up serology in RT-PCR-negative samples $(\mathrm{p}=0.1)$ did not significantly differ between the national Liechtenstein cohort and the Swiss validation cohort. When pooling the Liechtenstein and Swiss cases, the frequency of RT-PCR-positive samples with a negative follow-up serology was 3\% (5/151, 95\% CI $[1,8])$, whereas the frequency of RT-PCR-negative samples at first presentation together with positive follow-up serology amounted to $13 \%(28 / 220,95 \%$ CI $[9,18])$. 
Table 2: Characterization of patients from the population-based cohort with positive PCR at presentation and negative serology. (A) Laboratory results; (B) presenting clinical symptoms and signs.

\begin{tabular}{|c|c|c|c|c|c|c|c|c|c|c|c|}
\hline $\begin{array}{l}\text { Patient } \\
\text { number }\end{array}$ & $\begin{array}{l}\text { Age, } \\
\text { years }\end{array}$ & Sex & RT-PCR & $\begin{array}{r}\text { Time between PCR \& } \\
\text { serology, days }\end{array}$ & $\begin{array}{l}\text { N-ECLIA to- } \\
\text { tal Ig }\end{array}$ & $\begin{array}{r}\text { N- CMIA } \\
\text { IgG }\end{array}$ & $\begin{array}{r}\text { S- LIA } \\
\text { IgG }\end{array}$ & $\begin{array}{r}\text { S-ELISA } \\
\text { IgG }\end{array}$ & $\begin{array}{r}\text { S-ELISA } \\
\text { IgA }\end{array}$ & $\begin{array}{l}\text { N-ELISA } \\
\text { IgG }\end{array}$ & $\begin{array}{l}\text { N-ELISA } \\
\text { IgM }\end{array}$ \\
\hline 1 & 25 & $\mathrm{~F}$ & Pos & 53 & 0.1 & $<0.1$ & $<3.8$ & 0.5 & 0.5 & Neg & $\mathrm{Neg}$ \\
\hline 2 & 56 & $\mathrm{~F}$ & Pos & 54 & 0.1 & 0.1 & $<3.8$ & 0.2 & 0.5 & Neg & $\mathrm{Neg}$ \\
\hline 3 & 63 & $M$ & Pos & 53 & 0.1 & $<0.1$ & $<3.8$ & 0.3 & 0.7 & Neg & Neg \\
\hline
\end{tabular}

Table 2b: Characterization of patients from the population-based cohort with positive PCR at presentation and negative serology. (a) Laboratory results; (b) presenting clinical symptoms and signs.

\begin{tabular}{lrllllllll}
\hline $\begin{array}{l}\text { Patient } \\
\text { number }\end{array}$ & $\begin{array}{r}\text { Disease duration, Hospitalized } \\
\text { days }\end{array}$ & Fever $>38^{\circ}$ & Coughing & $\begin{array}{l}\text { Dyspnea } \\
\text { C }\end{array}$ & $\begin{array}{l}\text { Sore } \\
\text { throat }\end{array}$ & $\begin{array}{l}\text { Diarrhea } \\
\text { Limb pain/ } \\
\text { myalgia }\end{array}$ & $\begin{array}{l}\text { Anosmia/ } \\
\text { ageusia }\end{array}$ \\
\hline 1 & 20 & - & - & - & - & + & - & - & - \\
2 & 14 & - & + & - & - & + & + & - & - \\
3 & 38 & - & - & + & - & + & - & - & - \\
\hline
\end{tabular}

Table 3: Characterization of patients from the population-based cohort with negative PCR at first clinical presentation and positive follow-up serology. (A) Laboratory results; (B) presenting clinical symptoms and signs. A-D were index patients, E-K were household contacts, L was a close working contact.

\begin{tabular}{|c|c|c|c|c|c|c|c|c|c|c|c|}
\hline $\begin{array}{l}\text { Patient } \\
\text { number }\end{array}$ & $\begin{array}{l}\text { Age, } \\
\text { years }\end{array}$ & Sex & RT-PCR & $\begin{array}{r}\text { Time lag between PCR } \\
\text { and serology }\end{array}$ & $\begin{array}{r}\text { N-ECLIA to- } \\
\text { tal Ig }\end{array}$ & $\begin{array}{r}\text { N- CMIA } \\
\text { IgG }\end{array}$ & $\begin{array}{r}\text { S- LIA } \\
\text { IgG }\end{array}$ & $\begin{array}{r}\text { S-ELISA } \\
\text { IgG }\end{array}$ & $\begin{array}{r}\text { S-ELISA } \\
\text { IgA }\end{array}$ & $\begin{array}{l}\text { N-ELISA } \\
\text { IgG }\end{array}$ & $\begin{array}{l}\text { N-ELISA } \\
\text { IgM }\end{array}$ \\
\hline$A$ & 39 & $M$ & Neg & 57 & 16.8 & 3.3 & 156 & 3.5 & 1.5 & Pos & $\mathrm{Neg}$ \\
\hline B & 55 & $\mathrm{~F}$ & Neg & 47 & 24.1 & 2.8 & 40.6 & 0.3 & 0.4 & Pos & Pos \\
\hline C & 23 & $M$ & Neg & 37 & 18.4 & 4.4 & 84.7 & 6.4 & 11.2 & Pos & $\mathrm{Neg}$ \\
\hline D & 58 & $\mathrm{~F}$ & Neg & 52 & 3.2 & 1.3 & 34.3 & 3.2 & 2.2 & Neg & $\mathrm{Neg}$ \\
\hline$E$ & 55 & $\mathrm{~F}$ & Neg & 20 & 75.1 & 3.6 & 28.7 & 1 & 0.7 & Pos & $\mathrm{Neg}$ \\
\hline $\mathrm{F}$ & 51 & $M$ & $\mathrm{Neg}$ & 49 & 52.1 & 5.1 & 70.7 & 3.8 & 5.4 & Pos & $\mathrm{Neg}$ \\
\hline G & 51 & $\mathrm{~F}$ & Neg & 52 & 109.3 & 5.9 & 46.2 & 2.7 & 3.7 & Pos & Neg \\
\hline $\mathrm{H}$ & 35 & $\mathrm{~F}$ & Neg & 54 & 9.2 & 3.4 & 41 & 2.1 & 1.9 & Pos & $\mathrm{Neg}$ \\
\hline I & 24 & $\mathrm{~F}$ & Neg & 52 & 14.9 & 3.8 & 35.8 & 2.7 & 1.9 & Pos & $\mathrm{Neg}$ \\
\hline J & 37 & $\mathrm{~F}$ & Neg & 57 & 110.3 & 4.5 & 115 & 6.7 & 1.9 & Pos & $\mathrm{Neg}$ \\
\hline K & 57 & $M$ & $\mathrm{Neg}$ & 40 & 72.4 & 7.3 & 112 & 7 & 6.1 & Neg & Pos \\
\hline $\mathrm{L}$ & 42 & $M$ & Neg & 28 & 90.4 & 6.1 & 60.8 & 4.8 & 1.7 & Pos & $\mathrm{Neg}$ \\
\hline
\end{tabular}

\section{Discussion}

The present study suggests, that RT-PCR results at first clinical presentation and follow-up serology results differ in about one in five patients suffering from nonsevere COVID-19. Within the discrepant results, RT-PCR-negative results together with positive serology occurred more commonly than RT-PCR-positive results together with a negative follow-up serology. However, positive RT-PCR results without positive follow-up serology tended to be associated with a greater number of symptoms and longer disease duration than the other patients tested for COVID-19 by
RT-PCR. RT-PCR-negative results at presentation with positive follow-up serology were associated with fewer clinical symptoms than RT-PCR- and antibody-positive results.

The present study found a pooled COVID-19 prevalence of $13 \%$ of positive follow-up serology among the RT-PCR-negative patients at clinical presentation. These cases can be considered to represent false-negative RT-PCR results, as the predictivity of positive results by the use of several different testing formats in an orthogonal testing approach has been shown to be very high, making it an algorithm maximizes overall specificity while retaining maximum sensitivity [19]. Accordingly, a false negative 


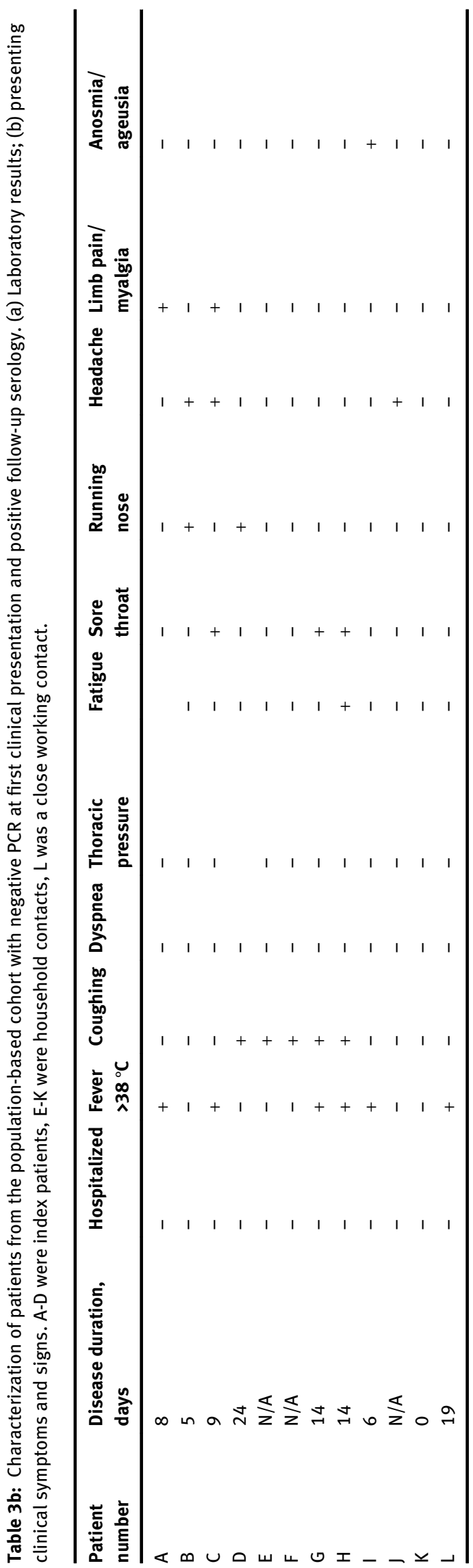

rate of $13 \%$ would translate into a sensitivity of $87 \%$. The specificity of the RT-PCR assay is considered to be very high $[1,13]$. Introducing a sensitivity of $87 \%$ together with an assumed specificity of $99.9 \%$ into the formula of Bayes's theorem would result in a negative predicate value (NPV) of $>99 \%$ at a $5 \%$ pretest probability, $99 \%$ at a pretest probability of $10 \%$, and $92 \%$ at a pretest probability of $40 \%$ [20]. Analogously, the probability of infection with a negative RT-PCR result at first presentation lies between $<1 \%$ (at $5 \%$ pretest probability) and $8 \%$ (at $40 \%$ pretest probability), depending on the pretest probability. Positive RT-PCR results have a predictive value of $98 \%$ at $5 \%$ pretest probability and $99 \%$ and more at pretest probabilities of $10 \%$ and above. The relationship between the predictive value of RT-PCR results and the pretest probabilities in the present setting is shown in Figure 2.

The false negative rate for the detection of COVID-19 in the present study is somewhat lower than that observed in a meta-analysis study by Kucirka and colleagues, which showed changing sensitivities depending on the time course of the infection and which ranged from 62 to $80 \%$ [13]. Long et al. reported a sensitivity of RT-PCR of $83 \%$, which seems comparable to the results of our study [15]. The determinants of false-negative results comprise biological factors (i.e., decreased viral shedding at the anatomic sampling site), sampling time (e.g., outside of diagnostic window, too early or too late), sample collection (e.g., insufficient quantity or quality of sampled material), sample handling (e.g., suboptimal swabs or transport medium, insufficient extraction), and analytical issues (e.g., viral load below the lower limit of detection of the assay, insensitive assay) [21].

The U.S. Food and Drug Administration has found the specificity of RT-PCR for the detection of COVID-19 to be $100 \%$ (reported in [13]). A potential cause of a lower specificity could be contamination with RNA from sources other than the patient under investigation during the testing process. Theoretically, the three cases in the Liechtenstein cohort could also have had false-positive RT-PCR results rather than been serological nonresponders. When looking at the clinical symptoms and the dates of occurrence of the symptoms of these patients, however, it becomes apparent that from a clinical perspective, the patients are very likely to have suffered from COVID-19. It appears that it is rather the negative antibody test results than the positive RT-PCR results that are implausible. A sample inversion during the preanalytical process could be ruled out with a second blood draw later, which also showed negative antibody results. It could also be possible that the antibodies had already disappeared 53 days after symptom onset. However, as there are other immune mechanisms leading to convalescence from COVID-19 (i.e., T-cell responses, 


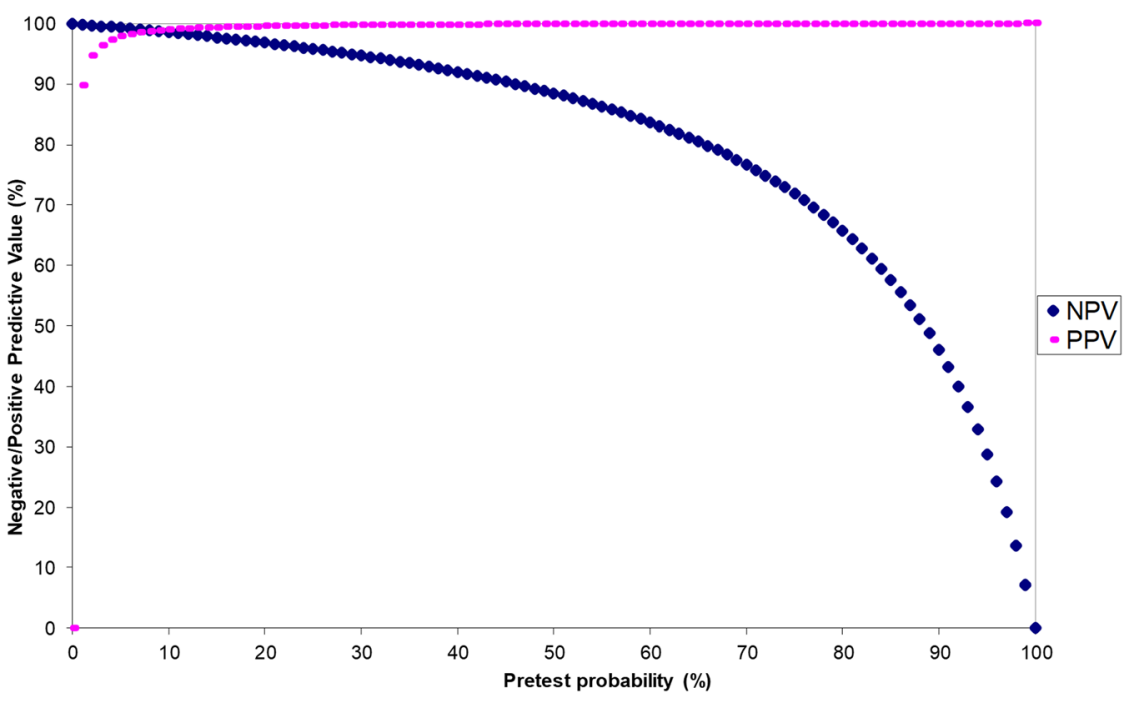

Figure 2: Positive (PPV) and negative predictive values (NPV) of RT-PCR for diagnosing COVID-19. A specificity of $99 \%$ was assumed. innate immunity, other cross-reactive antibodies), our data illustrate that either antibodies other than those measured in the employed immunoassays or a T-cell response without measurable antibodies would suffice to clear COVID-19 symptoms [22]. The fact that the three serological nonresponders had more symptoms than other COVID-19 patients and tended to have a longer disease course may suggest that there is suboptimal viral clearance in patients without a measurable antibody response. The frequency of such a subset of patients (i.e., 3\% of all RT-PCR-positive patients) was replicated in the Swiss cohort, which indicates that this phenomenon could be generalizable.

The fact that antibody titers and disease duration as well as the number of symptoms were consistently positively correlated may somehow be contradictory, as COVID-19 cases with no measurable antibodies had more disease symptoms and tended to have a longer disease duration. It could be that if patients are not able to mount a measurable humoral antibody response, this might be linked to reduced viral clearance, more organ systems involved, and a prolonged disease course. In this case, disease severity is a consequence of an irregular antibody response to the COVID-19 infection. If, on the other hand, a patient is able to produce measurable antibodies, disease severity and disease duration are positively correlated. In these patients, antibody titers can be regarded as a consequence of disease severity.

The present study has strengths and limitations. The circumstance, that we could demonstrate the absence of antibodies with seven different assays corroborates the theory of serological nonresponders, in whom a resolution of COVID-19 can be observed. Accordingly, the lack of SARS-CoV-2-specific antibodies is unlikely to be caused by a lack of a sensitive assay but rather by a biological phenomenon. The present study had the ability to analyze all the cases of a whole country and not just a sample of cases. We believe, that this makes the study less prone to the introduction of confounding factors. The fact that the false-negative RT-PCR rate and the serological nonresponder rate were reproduced in another cohort from a different country further strengthens our findings. A final strength is that the laboratory results in one of the cohorts were linked to clinical symptoms, allowing us to characterize serological non-responders more in detail. A limitation of the study is that the case number in this small country was relatively low, which comes along with relatively wide confidence intervals, when compared to those in larger studies. On the other hand, with a total of 362 cases studied in the two cohorts, the present study cannot be considered small. Finally, our findings were obtained in two middle European countries harboring a predominantly Caucasian population. It is possible that our findings cannot be extrapolated to other ethnicities. Furthermore, based on the inclusion criteria of symptomatic COVID-19 this study was not able to detect asymptomatic SARS-CoV-2 seroconversion. Overall, though, we believe that this limitation does not invalidate our findings.

In conclusion, our study described the frequency of false-negative RT-PCR in a population-based study setting and was validated in a separate cohort from another country. Further, we demonstrated the presence of patients with COVID-19 without any measurable antibody response. This constellation was associated with more symptoms and a tendency towards a longer disease course than in other COVID-19 patients. Although we reproduced the frequency of serological non-responders in a second cohort, the observed absolute number of cases is low. To further 
characterize the serological non-responder status, studies including larger numbers of affected individuals are needed.

\section{CRediT author statement}

Rita Christina Baron: Conceptualization, Methodology, Formal analysis, Writing - Original Draft; Lorenz Risch: Conceptualization, Methodology, Formal analysis, Writing Original Draft; Myriam Weber: Data curation, Validation, Resources; Sarah Thiel: Data curation, Validation, Resources; Kirsten Grossmann: Resources; Nadja Wohlwend: Investigation, Validation, Resources; Thomas Lung: Validation, Resources; Dorothea Hillmann: Investigation, Validation, Project administration, Resources; Michael Ritzler: Resources; Susanna Bigler: Validation, Resources; Konrad Egli: Validation, Resources; Francesca Ferrara: Resources; Thomas Bodmer: Validation, Resources; Mauro Imperiali: Validation, Resources; Sonja Heer: Validation, Resources; Yacir Salimi: Validation, Resources; Harald Renz: Conceptualization; Lukas Flatz: Conceptualization; Philipp Kohler: Validation, Writing - Original Draft; Pietro Vernazza: Conceptualization, Writing - Original Draft; Christian Kahlert: Conceptualization Writing - Original Draft; Matthias Paprotny: Supervision, Resources, Writing - Original Draft; Martin Risch: Conceptualization, Methodology, Funding acquisition, Supervision, Resources, Writing - Original Draft; All authors: Writing - Reviewing and Editing.

Acknowledgments: We thank Toni Schönenberger, Yvonne Weishäupl, and Walter Frehner for excellent IT-support.

Research funding: The research project was partly funded by a grant from the government of the Principality of Liechtenstein.

Author contributions: All authors have accepted responsibility for the entire content of this manuscript and approved its submission.

Competing interests: Authors state no conflict of interest. Informed consent: Informed consent was obtained from all individuals included in population based cohort from Liechtenstein. In the validation cohort, the institutional review board waived informed consent.

Ethical approval: Research involving human subjects complied with all relevant national regulations, institutional policies and is in accordance with the tenets of the Helsinki Declaration (as revised in 2013), and has been verified by the cantonal ethics commission Zürich (KEK ZH; BASEC Nr. Req-2020-00676) and ethics commission Eastern Switzerland (EKOS; BASEC Nr. Req2020-00586).

\section{References}

1. Patel R, Babady E, Theel ES, Storch GA, Pinsky BA, St George K, et al. Report from the American society for microbiology COVID-19 International summit, 23 march 2020: value of diagnostic testing for SARS-CoV-2/COVID-19. mBio 2020;11:00722-20.

2. Long QX, Liu BZ, Deng HJ, Wu GC, Deng K, Chen YK, et al. Antibody responses to SARS-CoV-2 in patients with COVID-19. Nat Med 2020;26:845-8.

3. Drame M, Tabue Teguo M, Proye E, Hequet F, Hentzien M, Kanagaratnam L, et al. Should RT-PCR be considered a gold standard in the diagnosis of COVID-19?. J Med Virol 2020. https:// doi.org/10.1002/jmv.25996. in press.

4. Stowell S, Guarner J. Role of serology in the COVID-19 pandemic. Clin Infect Dis 2020. https://doi.org/10.1093/cid/ciaa510. in press.

5. Theel ES, Slev P, Wheeler S, Couturier MR, Wong SJ, Kadkhoda K. The role of antibody testing for SARS-CoV-2: is there one?. J Clin Microbiol 2020;58:e00797-20.

6. To KK, Tsang OT, Leung WS, Tam AR, Wu TC, Lung DC, et al. Temporal profiles of viral load in posterior oropharyngeal saliva samples and serum antibody responses during infection by SARS-CoV-2: an observational cohort study. Lancet Infect Dis 2020;20:565-74.

7. Zhao R, Li M, Song H, Chen J, Ren W, Feng Y, et al. Early detection of SARS-CoV-2 antibodies in COVID-19 patients as a serologic marker of infection. Clin Infect Dis 2020. https://doi.org/10. 1093/cid/ciaa523. in press.

8. Mallapaty S. Will antibody tests for the coronavirus really change everything?. Nature 2020;580:571-2.

9. Vashist SK. Vitro diagnostic assays for COVID-19: recent advances and emerging trends. Diagnostics 2020;10:202.

10. Guo L, Ren L, Yang S, Xiao M, Chang D, Yang F, et al. Profiling early humoral response to diagnose Novel coronavirus disease (COVID-19). Clin Infect Dis 2020;71:778-85.

11. Fierz W, Walz B. Antibody dependent enhancement due to original antigenic sin and the development of SARS. Front Immunol 2020;11:1120.

12. Woloshin S, Patel N, Kesselheim AS. False negative tests for SARS-CoV-2 infection - challenges and Implications. N Engl J Med 2020;383:e38. in press.

13. Kucirka LM, Lauer SA, Laeyendecker O, Boon D, Lessler J. Variation in false-negative rate of reverse transcriptase polymerase chain reaction-based SARS-CoV-2 tests by time since exposure. Ann Intern Med 2020:M20-1495. https://doi.org/10.7326/M20-1495.

14. Watson J, Whiting PF, Brush JE. Interpreting a covid-19 test result. BMJ 2020;369:m1808.

15. Long C, Xu H, Shen Q, Zhang X, Fan B, Wang C, et al. Diagnosis of the Coronavirus disease (COVID-19): rRT-PCR or CT?. Eur J Radiol 2020;126:108961.

16. Covid-19. Why test? Who to test? How to test? Bull Acad Natl Med 2020. https://doi.org/10.1016/j.banm.2020.05.006. in press.

17. Danis K, Epaulard O, Benet T, Gaymard A, Campoy S, BotelhoNevers E, et al. Cluster of coronavirus disease 2019 (COVID-19) in the French alps, February 2020. Clin Infect Dis 2020;71:825-32.

18. Tang MS, Hock KG, Logsdon NM, Hayes JE, Gronowski AM, Anderson NW, et al. Clinical performance of two SARS-CoV-2 serologic assays. Clin Chem 2020;66:1055-62.

19. Centers for disease prevention and control. Interim guidelines for COVID-19 antibody testing; 2020. Available from: https://www. 
cdc.gov/coronavirus/2019-ncov/lab/resources/antibody-testsguidelines.html [Accesed 19 June 2020].

20. Risch L, Monn A, Luthy R, Honegger H, Huber AR. The predictive characteristics of $D$-dimer testing in outpatients with suspected venous thromboembolism: a Bayesian approach. Clin Chim Acta 2004;345:79-87.
21. Valent F, Doimo A, Mazzilis G, Pipan C. RT-PCR tests for SARS-CoV2 processed at a large Italian Hospital and false-negative results among confirmed COVID-19 cases. Infect Control Hosp Epidemiol 2020:1-2. https://doi.org/10.1017/ice.2020.290.

22. St John AL, Rathore APS. Early Insights into immune responses during COVID-19. J Immunol 2020;205:555-64. 